\title{
Práticas Pedagógicas no Processo de Reabilitação de Alunos com Surdocegueira
}

\author{
Pedagogical Practices in the Rehabilitacion Process of Deafblind Students
}

Prácticas pedagógicas en el proceso de rehabilitación de estudiantes con sordoceguera

\section{* Thaís Ferreira Bigate}

Professora Mestre no Instituto Benjamin Constant. Rio de Janeiro, Rio de Janeiro, Brasil.

thaisbigate@yahoo.com.br

\section{** Neuza Rejane Wille Lima}

Professora doutora na Universidade Federal Fluminense, Rio de Janeiro, Rio de Janeiro, Brasil.

rejane_lima@id.uff.br

Recebido em 13 de setembro de 2018

Aprovado em 19 de setembro de 2018

Publicado em 05 de junho de 2019

\section{RESUMO}

O presente estudo buscou analisar as práticas pedagógicas empregadas no processo de reabilitação de alunos com surdogueira do Instituto Benjamin Constant. A surdocegueira é uma deficiência que compromete os principais sentidos de recepção de informação, logo, os professores devem utilizar práticas distintas daquelas usadas com os demais alunos com deficiência visual e, se a população surdocega tem como principal característica a heterogeneidade, deve existir diferenças nos atendimentos de alunos que apresentam distinto período de aquisição da deficiência e de graus de perda da audição e da visão. A fim de compreender esse processo, o estudo de caso foi selecionado como metodologia e a coleta de dados foi realizada por meio de levantamento bibliográfico e entrevista semiestruturada. Concluiu-se que a principal dificuldade encontrada pelos professores foi a comunicação e que a presença de um tradutor e intérprete de Língua Brasileira de Sinais (Libras) é fundamental nesse contexto. As ações mencionadas pelos professores foram consideradas relevantes, possibilitando o acesso dos alunos com surdocegueira aos conteúdos das aulas.

Palavras-chave: Surdocegueira; Práticas pedagógicas; Reabilitação.

\section{ABSTRACT}

The present study sought to analyze the pedagogical practices employed in the process of rehabilitation of deafblind students from Instituto Benjamin Constant. Deafblindness is a disability that compromises the main senses of receiving information, so the teacher should use different tasks from the ones used with the other visually impaired students and, if deafblind population has as its main characteristic heterogeneity, there must exist 
differences in the attendance of students that present different periods of disability acquisition and varied degrees of hearing loss and vision. In order to better understand this process, case study was selected as methodology and data collection was carried out through bibliographic survey and semi-structured interview. It was concluded that the main challenge found by the teachers was communication and the presence of a translator of Brazilian Sign Language (Libras) is fundamental in this context. The practices mentioned by the teachers were considered relevant, as they allowed the deafblind students' access to the content of the classes.

Keywords: Deafblindness; Pedagogical practices; Rehabilitation.

\section{RESUMEN}

El presente estudio buscó analizar las prácticas pedagógicas empleadas en el proceso de rehabilitación de estudiantes con sordoceguera del Instituto Benjamín Constant. La sordoceguera es una deficiencia que compromete los principales sentidos de recepción de información, luego los profesores deben utilizar prácticas distintas de aquellas usadas con los demás estudiantes con deficiencia visual y, si la población sordocega tiene como principal característica la heterogeneidad, debe existir diferencias en las atenciones de estudiantes que presentan distinto período de adquisición de la discapacidad y de grados de pérdida de la audición y de la visión. A fin de comprender este proceso, el estudio de caso fue seleccionado como metodología y la recolección de datos fue realizada por medio de levantamiento bibliográfico y entrevista semiestructurada. Se concluyó que la principal dificultad encontrada por los profesores fue la comunicación y que la presencia de un traductor e intérprete de Lengua Brasileña de Señales (Libras) es fundamental en ese contexto. Las acciones mencionadas por los profesores fueron consideradas relevantes, posibilitando el acceso de los estudiantes con sordoceguera a los contenidos de las clases Palabras clave: Sordoceguera; Prácticas pedagógicas; rehabilitación.

\section{Características da surdocegueira}

A surdocegueira é caracterizada pela perda coexistente e significativa dos sentidos da visão e da audição. Trata-se de uma deficiência única, em que não há compensação ${ }^{1}$ do déficit auditivo pela visão, tampouco do déficit visual pela audição, o que resulta em problemas de comunicação, informação e mobilidade. Conforme a organização não governamental Grupo Brasil de Apoio ao Surdocego e ao Múltiplo Deficiente Sensorial,

\footnotetext{
${ }^{1}$ Segundo Vygotsky, quando há um “defeito ou problema físico" de qualquer natureza, "o defeito age como um incentivo para aumentar o desenvolvimento de outras funções no organismo. [...] ele ativa, desperta o organismo para redobrar atividade, que compensará o defeito e superará a dificuldade.” O organismo exige mais dos sentidos remanescentes para compensar a ausência de outro. (VYGOTSKY, 1989, p.54)
} 
Surdocegueira é uma deficiência singular que apresenta perdas auditivas e visuais concomitantemente em diferentes graus, levando a pessoa com surdocegueira a desenvolver diferentes formas de comunicação para entender e interagir com as pessoas e o meio ambiente, para ter acesso a informações, uma vida social com qualidade, orientação, mobilidade, educação e trabalho. (GRUPO BRASIL, 2007 apud MAIA, 2011, p. 51)

A linguagem e a comunicação são desafios na surdocegueira. Tantas especificidades resultam em várias possibilidades de linguagem para a comunicação do sujeito com o mundo, sendo alvo de grande interesse nos estudos sobre surdocegueira.

Estas são algumas das formas de comunicação utilizadas por esse público (WATANABE, 2017, p. 105):

- Língua de sinais tátil: língua de sinais percebida pelo tato da pessoa com surdocegueira;

- Língua de sinais em campo reduzido - língua de sinais em espaço menor e com distância variada de acordo com a condição visual da pessoa surdocega.

- Braille tátil:Braille adaptado para que possa ser percebido pelo tato. Sistema em que os dedos indicador e médio representam a cela Braille ${ }^{2}$ e cada falange, o espaço de marcação dos pontos, viabilizando que palavras sejam escritas nos dedos dos que dominam a técnica. Em outra adaptação, os dedos indicador, anelar e médio de ambas as mãos representam os seis pontos do Braille de uma cela imaginária, que serão tocados pelo interlocutor.

- Escrita na palma da mão: usar o dedo como lápis para escrever na palma da mão da pessoa surdocega, geralmente em letras de forma.

- Fala ampliada: fala próxima ao melhor ouvido da pessoa com surdocegueira.

- Tadoma: a pessoa surdocega toca com a mão no rosto - queixo e pescoço - da pessoa que está falando, percebendo as vibrações da fala e movimentos fonoarticulatórios.

- Alfabeto manual tátil: alfabeto manual feito na palma da mão.

- Pranchas de comunicação: prancha com letras em relevo ou em Braille para que o dedo indicador da pessoa com surdocegueira seja conduzido até as letras para formas palavras.

\footnotetext{
${ }^{2}$ A cela é formada por duas colunas e três linhas de pontos. A localização dos pontos é dada de cima para baixo, primeiramente na coluna da esquerda e posteriormente na coluna da direita e são denominados respectivamente pontos números 1, 2, 3, 4, 5 e 6. Cada combinação de pontos em relevo forma, portanto, determinada letra ou sinal de pontuação. (NICOLAIEWSKY; CORREA, 2008, p. 231)
} 
- Objetos de referência: objetos significativos da rotina que indicam pessoas, ações, lugares e tempo.

- Expressões/Gestos Naturais: expressos por sons, vocalizações ou movimentos, como choro, sorriso, movimento corporal, expressões corporais e faciais.

- Sinais Personalizados: sinais criados pelas pessoas com surdocegueira e seus parceiros de comunicação.

\section{O processo de reabilitação}

O aparecimento ou aquisição de qualquer deficiência na vida adulta pode implicar um processo de adaptação à nova condição. O programa de reabilitação constitui um conjunto de ações que busca reeducar seus alunos considerando sua nova realidade. Para isso, como em qualquer outra ação pedagógica, deve respeitar a individualidade, a potencialidade, o interesse e o desenvolvimento psicológico-social do educando (BRASIL, 2001).

A Lei Brasileira de Inclusão afirma que é dever do Estado, da sociedade e da família assegurar à pessoa com deficiência, dentre outros direitos, a reabilitação. Segundo a lei, o processo de reabilitação

[...] tem por objetivo o desenvolvimento de potencialidades, talentos, habilidades, aptidões físicas, cognitivas, sensoriais, psicossociais, atitudinais, profissionais e artísticas que contribuam para a conquista da autonomia da pessoa com deficiência e de sua participação social em igualdade de condições e oportunidades com as demais pessoas. (BRASIL, 2015)

Para tanto, esse trabalho é desenvolvido por equipe multidisciplinar formada por profissionais de educação e saúde e, não menos importante, com a participação da família.

Os profissionais que realizam o trabalho de reabilitação são médico oftalmologista e clínico, com avaliação inicial, acompanhamento e indicação de recursos ópticos que melhoram a resolução de imagens nos casos de haver resíduo visual; assistente social, com levantamentos relevantes para o processo, encaminhamento e orientação aos atendimentos e orientação familiar; psicólogo, com avaliação psicológica, orientação quanto ao programa, acompanhamento e orientação psicológica ao reabilitando ${ }^{3}$ e à família; professores especializados em Braille, soroban ${ }^{4}$, informática com recursos adaptados para pessoas com deficiência visual, orientação e mobilidade, educação física

\footnotetext{
${ }^{3}$ Os alunos de programas de reabilitação também são comumente chamados de reabilitandos.

${ }^{4}$ Instrumento manual para fazer cálculos matemáticos.
} 
e artes; e terapeutas, que inclui fisioterapeutas, terapeutas ocupacionais e fonoaudiólogo para deficiências associadas. (BRASIL, 2001)

Quando se trata de alunos com surdocegueira, a equipe multidisciplinar deve contar com professores com capacitação em Língua Brasileira de Sinais (Libras) e tradutor e intérprete de LIBRAS com capacitação em guia-interpretação. Dessa forma, poderá atender os alunos de acordo com suas especificidades no que se refere à linguagem e à comunicação.

O Instituto Benjamin Constant (IBC) foi em 1854, durante o império de Dom Pedro II com o nome de Imperial Instituto de Meninos Cegos. O IBC foi primeira instituição na América Latina destinada ao ensino de pessoas com deficiência, especificamente a deficiência visual. Além de dedicar-se à Educação Básica, a Instituição também oferece a comunidade o serviço de Reabilitação pelo O Departamento de Estudos e Pesquisas Médicas e de Reabilitação (DMR). Nesse Departamento, há um programa específico para alunos com surdocegueira - o Programa de Atendimento e Apoio ao Surdocego (PAAS), que foi criado em 1993 com o nome de Programa Piloto de Atendimento ao Deficiente Auditivo-Visual. O PAAS atende alunos com surdocegueira congênita e adquirida, respeitando suas especificidades comunicacionais, sua funcionalidade e seus interesses. No programa, os alunos podem ter aulas individuais de Braille, soroban e aprender outras formas de comunicação além das que o aluno já utiliza ou ampliar a linguagem já existente. Além disso, os profissionais do programa, professores e guia-intérprete, acompanham os alunos nas demais aulas e atividades oferecidas pela Programa de Reabilitação, possibilitando a inclusão em turmas de deficientes visuais ou mediando a comunicação em aulas individuais como orientação e mobilidade, bem como atividades pedagógicas, culturais, artísticas e sociais desenvolvidas ao longo do processo de reabilitação.

\section{Práticas pedagógicas}

A prática pedagógica é compreendida como uma prática social conduzida por objetivos, finalidades e conhecimentos. Considerando o contexto social, ela presume uma relação teoria-prática em que ambas se influenciam e podem gerar modificações uma na outra, havendo, assim, uma dependência mútua entre teoria e prática.

O aspecto teórico é configurado por ideias que são sistematizadas a partir da prática e/ou anseios baseados no cotidiano de vida e trabalho. O aspecto prático é composto de 
meios pelos quais as teorias pedagógicas são colocadas em ação. Enquanto a primeira está no campo ideal, teórico, idealizado, a segunda está no campo real, objetivo, material. Segundo Veiga,

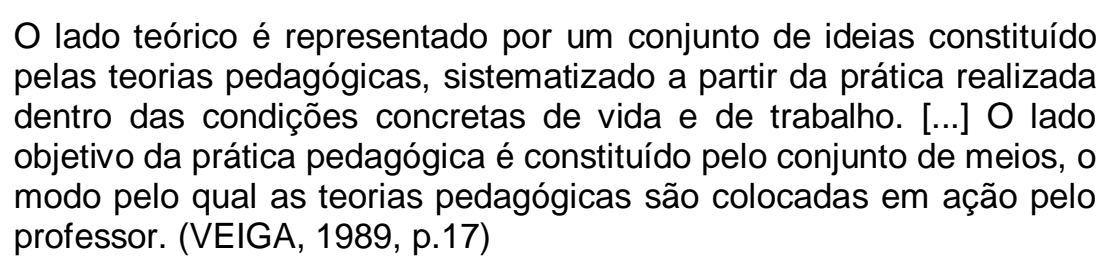

Esse conjunto de meios também está relacionado a questões materiais, vivências e recursos didáticos empregados em sala de aula. Esses aspectos, que integram a prática pedagógica, são de suma importância para a efetiva inclusão. Adaptações, criação de materiais específicos, reorganização temporal e espacial, com a intencionalidade de atender a diversidade oportunizam aprendizagens significativas.

Essa possibilidade de personalizar o ensino, respeitando as dificuldades e os talentos dos alunos, a partir do uso de estratégias pedagógicas diferenciadas, pode ampliar consideravelmente a inclusão com desenvolvimento acadêmico e social do sujeito com deficiências. (PLETSCH, SOUZA E ORLEAN, 2017, p. 273)

Com as devidas adequações, é possível incluir o aluno com deficiência nas situações de aprendizagem que os demais estão vivendo. Atender às diferenças individuais que o estudante possa apresentar viabiliza a igualdade ao acesso e permanência na escola a que todos têm direito.

A perspectiva desta pesquisa reflete no lado objetivo da prática pedagógica, visando às ações docentes para que o aluno com surdocegueira participe ativamente das atividades educacionais oferecidas pelo Programa de Reabilitação do IBC. Nesse contexto, o lado teórico não foi excluído, contudo, a questão do estudo teve como foco a perspectiva prática, o "como", os procedimentos para que o discente com surdocegueira possa realizar as atividades e atingir os propósitos assim como os demais alunos.

\section{O percurso metodológico da pesquisa}

Com base nos objetivos traçados, o estudo de caso foi selecionado como metodologia mais adequada, uma vez que o procedimento é empregado em circunstâncias em que se buscam compreender fenômenos sociais complexos, sejam eles de natureza individual, organizacional, social, político e de grupo.

Para Yin (2005), 
Em geral, os estudos de caso representam a estratégia preferida quando se colocam questões do tipo "como" e "por que", quando o pesquisador tem pouco controle sobre os acontecimentos e quando o foco se encontra em fenômenos contemporâneos inseridos em algum contexto da vida real. (YIN, 2005, p. 26)

Nesse caso, o fenômeno complexo inserido em contexto real é o atendimento de alunos com surdocegueira no Programa de Reabilitação que ocorre no Instituto Benjamin Constant. A principal questão é como esse atendimento é realizado especificamente por parte dos professores. A formulação da questão ou formulação do problema, como é denominada por Gil (2002), surge de um longo processo de reflexão e de pesquisa bibliográfica. O contato direto da pesquisadora com os professores do Programa de Reabilitação e o levantamento bibliográfico sobre a temática foram essenciais para seleção e delimitação da questão de estudo.

Além da questão do estudo, segundo Yin (2005), também pode haver proposições que auxiliam na procura de evidências relevantes para estudo. No caso em questão, pressupõe-se que, se a surdocegueira é uma deficiência que compromete os principais sentidos de recepção de informação, os professores devem utilizar práticas distintas daquelas usadas com os demais alunos com deficiência visual e, se a população surdocega tem como principal característica a heterogeneidade, deve existir diferenças nos atendimentos de alunos que apresentam distintos períodos de aquisição da deficiência e graus de perda da audição e da visão.

Considerando as proposições e a questão do estudo, a unidade de análise foi um grupo de professores lotado na Divisão de Reabilitação que ministra ou ministrou aulas para alunos com surdocegueira. Foi dada prioridade àqueles profissionais que atenderam a mais de um estudante e com características diferentes no que se refere à deficiência. Outro critério de seleção foi a área de atuação, sendo convidados docentes com formações diversas. Além dos professores, também foi entrevistado o tradutor e intérprete de Libras da Instituição, visto que a profissional exerce uma função importantíssima que é a mediação da comunicação entre professores e alunos.

Considerando o interesse em levantar e relatar informações acerca das práticas pedagógicas utilizadas pelos professores para 0 atendimento de alunos com surdocegueira, as questões suscitadas foram:

- Quando e onde foi seu primeiro contato com alunos com surdocegueira?

- Quais as dificuldades encontradas no atendimento a esse público? 
- Quais práticas pedagógicas foram empregadas para a inclusão/participação desse aluno em suas aulas?

Foram convidados e aceitaram participar do estudo oito professores e um tradutor e intérprete de Libras. Em relação às práticas pedagógicas, foram analisadas as entrevistas de seis professores dos seguintes atendimentos: Orientação e Mobilidade, Artes (dois), Educação Física, Braille e Informática Educativa.

\title{
Coleta e análise de dados
}

Ao selecionar o corpus da pesquisa foram identificadas as práticas pedagógicas mais recorrentes no atendimento dos discentes com surdocegueira. Posteriormente, as práticas foram classificadas em categorias de acordo com seus aspectos em comum. Conforme Bardin,

\begin{abstract}
Classificar elementos em categorias impõe a investigação do que cada um deles tem em comum com outros. O processo classificatório possui importância considerável em toda e qualquer actividade científica. A partir do momento em que a análise de conteúdo decide codificar o seu material, deve produzir um sistema de categorias. A categorização tem com primeiro objectivo, fornecer, por condensação, uma representação simplificada dos dados brutos. (BARDIN, 1973, p.119)
\end{abstract}

Desse modo, o agrupamento de elementos a partir de características comuns pode facilitar a compreensão e a exposição dos dados coletados. Neste estudo, especificamente, a categorização teve por objetivo simplificar e organizar a discussão dos dados da pesquisa.

\section{Entrevistas}

\section{Professor de Informática Educativa}

O professor de Informática Educativa teve seu primeiro contato com alunos com surdocegueira no IBC no ano de 2017. O mesmo recebeu em sua classe, em períodos diferentes, dois alunos com graus de perdas sensoriais distintos. Um dos alunos tinha baixa audição e era cego. A forma de comunicação usada era a fala ampliada. O professor necessitava falar mais alto e próximo ao aluno e o mesmo conseguia compreender com sua audição residual. $\mathrm{O}$ outro, surdo e com baixa visão. Sua forma de comunicação era a Libras em campo reduzido.

- Relato do docente:

A maior dificuldade que encontrei foi minha lacuna na formação do uso da Libras e, por isso, fico muito dependente do acompanhamento da intérprete. 
Quando começamos a trabalhar com os alunos da surdocegueira, tivemos uma grande dificuldade, porque o material que a gente usa, que é o Software Digitavox, é todo baseado em áudio, para os exercícios de domínio do teclado. Nós tivemos então que fazer a adaptação do material didático.

[...] Foi quando elaboramos esse pequeno Software, muito simples, mas baseado na visão residual que a aluna tinha. Utilizamos também sinais de Libras, o alfabeto com a palavra escrita e a imagem. Faltou acrescentar, como a gente tinha planejado, o vídeo... o vídeo de um intérprete de Libras. Não foi muito necessário, porque a aluna demonstrou domínio do teclado com muita rapidez.

\section{Professor de Artes (Cerâmica)}

O professor de Artes teve seu primeiro contato com alunos com surdocegueira no IBC no ano de 2014. O profissional relatou ter recebido em suas turmas, ao longo desse período (2014 a 2018), alunos com graus de perdas sensoriais distintos.

- Trechos da entrevista do docente:

A primeira dificuldade que eu encontrei neste contato foi a questão da comunicação, embora a gente tivesse a ferramenta de ter o aporte, o suporte da professora e da intérprete, eu senti necessidade de estar trabalhando com este aluno diretamente alguns conceitos no processo ensino-aprendizagem, o que é importante, então eu busquei um curso de Libras $[\ldots]$.

A outra dificuldade que eu encontrei, e ainda não considero superada, é a questão dos materiais, a adaptação de materiais, embora a gente tenha aqui também o Departamento de materiais e eu tenha cumprido também cursos para esse Departamento, ainda acredito que nós precisamos pensar em estratégias para a pessoa com surdocegueira individuais, porque cada pessoa ela é um indivíduo, então vai apresentar uma gradação de cegueira ou de surdez diferenciada. Isso muda também o material que eu vou trabalhar [...].

As práticas pedagógicas para os alunos com surdocegueira, elas seguem as mesmas práticas dos outros alunos cegos ou com baixa visão.

[...]É claro que eu acredito que se não tivéssemos um setor específico para esse aluno, que ele tivesse essa aula, a coisa seria muito mais difícil. Eu acho que a partir do momento que você tem professores que trabalham com professores, tudo vai se encaixando. 


\section{Professor de Orientação e Mobilidade}

O professor de Orientação e Mobilidade teve seu primeiro contato com alunos com surdocegueira no IBC no ano de 2004. O profissional ministra aulas para dois alunos com perfis de perdas sensoriais e formas de comunicação diferentes. Um dos alunos tem baixa audição e baixa visão. A forma de comunicação usada é a fala ampliada. O outro, surdo e com baixa visão, sua forma de comunicação é a Libras em campo reduzido, sendo necessária a presença da tradutora e intérprete da língua de sinais.

- Trechos da entrevista do docente:

E dentro dessas comunicações que nós estamos fazendo, a que tem resíduo auditivo, eu tenho contato, eu não preciso da intérprete para passar as informações para ela. Já a que não tem o resíduo auditivo, eu necessito do intérprete, para passar as informações mais precisas.

[...] durante o desenvolver das atividades, eu procuro trabalhar com a demonstração, pegando na mão do aluno e demonstrando para o aluno como o movimento deve ser feito. Então, eu procuro, e o intérprete em si, ele dá o reforço para mim, ele vai, eu demonstro para ele e o intérprete dá o reforço da palavra, da língua para esse aluno.

\section{Professor de Artes (Artes Visuais)}

O professor de Artes teve seu primeiro contato com alunos com surdocegueira no IBC. Em sua primeira experiência, o profissional não teve o suporte de um tradutor e intérprete de Libras.

- Trechos da entrevista do docente:

Eu tenho uma aluna surdocega que a primeira língua dela é a Libras. E de uns dois meses para cá, eu percebi que a grande dificuldade dela não era o Sistema Braille. Ela já vinha entendendo a lógica do Sistema, mas na hora de colocar em prática, tanto na escrita, quanto na leitura, ela apresentava uma dificuldade muito grande. E aí eu percebi que a dificuldade era a língua portuguesa. Então eu comecei a obedecer à estrutura da primeira língua dela, que é a Libras, e começou a dar super certo. Então ela vem se desenvolvendo muito bem depois dessa mudança que a gente teve.

[...]O aluno, por exemplo, que tem resíduo auditivo, a gente tem uma preocupação de dar essa aula em um ambiente silencioso e conversar com esse aluno para saber se ele está entendendo direitinho, se ele está ouvindo. É esse aluno que vai dar esse feedback para a gente, se precisa aumentar o tom de voz ou não, então há esse diálogo. As aulas 
com esse aluno com resíduo auditivo não difere muito das aulas do aluno que tem a deficiência visual. O que vai diferenciar é isso mesmo, é o local e esse feedback do aluno, se ele está escutando ou não e como está sendo o andamento da aula. Para o aluno surdocego total, aquele que não tem nem resíduo auditivo e nem resíduo visual, que ainda não compreende alguns conceitos, que tem o vocabulário reduzido, nós podemos trabalhar com material concreto para facilitar o processo de aprendizagem do Sistema Braille.

\section{Professor de Educação Física}

O professor de Educação Física teve seu primeiro contato com alunos com surdocegueira no IBC. Ministrou aulas individuais para um aluno com perda total da visão e da audição e que se comunicava com sinais caseiros. As atividades eram realizadas em ambiente aquático e a comunicação era direta entre professor e aluno. No decorrer das atividades, o discente comunicava-se por meio de expressões faciais e corporais, dessa forma, o docente conseguia perceber se o aluno estava satisfeito com as atividades ou não.

Outros dois alunos foram atendidos em uma turma com pessoas com deficiência visual. O primeiro comunicava-se por meio da fala ampliada, ou seja, bastava que o professor falasse mais alto e próximo ao aluno para que ele entendesse os comandos para realização das atividades. O segundo aluno era usuário da língua de sinais, logo, a presença do intérprete era importante para auxiliar na comunicação entre professor e aluno.

- Trechos da entrevista do docente:

A partir do contato com esses alunos, eu busquei capacitação. Então umas das capacitações que eu busquei foi o curso de Libras no Instituto Nacional de Educação de Surdos, o qual eu ainda faço, faltam seis meses para finalizar, se eu não me engano, e uma outra forma de capacitação, que eu entendo como uma formação continuada, promovida pelo próprio Instituto Benjamin Constant, é dentro da nossa carga horária, a gente poder trabalhar com grupos de pesquisa. [...] ali nesse grupo, a gente trabalha a nossa prática dentro do Instituto Benjamin Constant. E uma das nossas práticas, minha e dos outros integrantes, é a surdocegueira.

\section{Discussão das entrevistas}

Como mencionado nesta pesquisa, a prática pedagógica é compreendida como uma prática social conduzida por objetivos, finalidades e conhecimentos com uma relação 
teórico-prática, em que a teoria consiste no plano das ideias e a prática no plano das ações. (VEIGA, 1989)

Todas as ações mencionadas pelos entrevistados objetivando a participação e a inclusão dos alunos com surdocegueira são consideradas práticas pedagógicas; dessa forma, foram apreciadas todas as ações docentes que incidiram no processo de ensinoaprendizagem dos alunos com surdocegueira.

A diversidade é considerada natural e salutar, como afirma Cambruzzi e Costa (2016), e cabe à escola pensar nesse aspecto tão relevante. O relato dos professores demonstra como é importante pensar na heterogeneidade, tanto ao que se refere às distinções entre os alunos com deficiência visual e os com surdocegueira, quanto às diferenças entre os discentes com a mesma deficiência.

O quadro 1 mostra com mais clareza as práticas pedagógicas empregadas pelos professores participantes da pesquisa.

Quadro 1 - Resultado da pesquisa

\begin{tabular}{|c|c|c|c|c|c|c|}
\hline $\begin{array}{l}\text { PRÁTICAS } \\
\text { PEDAGÓGICAS }\end{array}$ & $\begin{array}{l}\text { Prof. A } \\
\text { Informática } \\
\text { Educativa }\end{array}$ & $\begin{array}{l}\text { Prof. B } \\
\text { Artes } \\
\text { (cerâmica) }\end{array}$ & $\begin{array}{l}\text { Prof. C } \\
\text { O.M. }\end{array}$ & $\begin{array}{l}\text { Prof.D } \\
\text { Artes } \\
\text { Visuais }\end{array}$ & $\begin{array}{l}\text { Prof. E } \\
\text { Braille }\end{array}$ & $\begin{array}{l}\text { Prof. F } \\
\text { Educação } \\
\text { Física }\end{array}$ \\
\hline $\begin{array}{l}\text { Adaptação de } \\
\text { material didático }\end{array}$ & $\checkmark$ & & & & $\checkmark$ & \\
\hline $\begin{array}{l}\text { Adaptação de } \\
\text { método de ensino }\end{array}$ & & & & $\checkmark$ & $\checkmark$ & \\
\hline $\begin{array}{l}\text { Auxílio de intérprete } \\
\text { Libras }\end{array}$ & $\checkmark$ & $\checkmark$ & $\checkmark$ & $\checkmark$ & & $\checkmark$ \\
\hline $\begin{array}{l}\text { Trabalho } \\
\text { colaborativo }\end{array}$ & & $\checkmark$ & & & & \\
\hline Modulação de voz & $\checkmark$ & & $\checkmark$ & & $\checkmark$ & $\checkmark$ \\
\hline Instruções táteis & & $\checkmark$ & $\checkmark$ & $\checkmark$ & $\checkmark$ & $\sqrt{ }$ \\
\hline Curso de Libras & & $\checkmark$ & & & $\checkmark$ & $\checkmark$ \\
\hline $\begin{array}{l}\text { Participação em } \\
\text { grupos de } \\
\text { pesquisa }\end{array}$ & & $\checkmark$ & & $\checkmark$ & & $\checkmark$ \\
\hline $\begin{array}{l}\text { Atividades } \\
\text { individualizadas }\end{array}$ & & $\sqrt{ }$ & & $\sqrt{ }$ & & \\
\hline Material concreto & & & & $\checkmark$ & $\checkmark$ & \\
\hline
\end{tabular}

Fonte: Autores. 
O quadro 2 apresenta as práticas pedagógicas separadas por categorias, considerando as características comuns dos elementos. As práticas relacionadas à forma como é estabelecida a comunicação entre professor e aluno, sejam elas diretas ou mediadas, foram chamadas de comunicação; as ações referentes à formação continuada ${ }^{5}$ dos profissionais para atuarem com os alunos com surdocegueira, anteriores ao ingresso no IBC ou durante o exercício na instituição, foram denominadas capacitação profissional; e os procedimentos relativos aos materiais usados nas aulas e as adaptações de métodos de ensino foram intitulados materiais e métodos.

Tabela 1 - Categorização das práticas pedagógicas

\begin{tabular}{l|l}
\hline CATEGORIAS & PRÁTICAS PEDAGÓGICAS \\
\hline Comunicação & $\begin{array}{l}\text { Auxílio de intérprete de Libras; Modulação de } \\
\text { voz; Instruções táteis }\end{array}$ \\
\hline | Capacitação profissional & $\begin{array}{l}\text { Curso de Libras; Participação em grupo de } \\
\text { pesquisa }\end{array}$ \\
\hline Materiais e métodos & $\begin{array}{l}\text { Adaptação de material didático; Adaptação de } \\
\text { método de ensino; Material concreto; } \\
\text { Atividades individualizadas; Trabalho } \\
\text { colaborativo }\end{array}$ \\
\hline
\end{tabular}

Fonte: Autores

\section{Comunicação}

Os profissionais de Informática Educativa, O.M. e Artes Visuais mencionaram que "dependem" do intérprete de Libras por não dominarem a língua. Apesar de relatarem estabelecer alguma comunicação e até conseguirem desenvolver algumas atividades com base em modelos concretos, o ensino de conceitos só é viável com a presença do tradutor e intérprete.

Quanto ao tradutor e intérprete de Libras, a presença de apenas um profissional no quadro da Instituição pode dificultar a acessibilidade dos alunos. Em algumas atividades, os professores do PAAS e o intérprete fazem a mediação na comunicação, isso ocorre nos horários em que há mais de um aluno com surdocegueira na mesma turma ou realizando

\footnotetext{
${ }^{5} \mathrm{O}$ conceito ora se restringe o significado da expressão aos limites de cursos estruturados e formalizados oferecidos após a graduação, ou após ingresso no exercício do magistério, ora ele é tomado de modo amplo e genérico, como compreendendo qualquer tipo de atividade que venha a contribuir para o desempenho profissional. (GATTI, 2008)
} 
atividades distintas. A falta de conhecimento a respeito da função também pode gerar incômodo nos professores que não estão acostumados com a presença desse profissional em suas aulas.

Apesar de ainda não vigorar medida legal em âmbito nacional que disponha sobre o revezamento de profissionais durante a tradução e interpretação, tramita na câmara de deputados de Brasília o Projeto de Lei no 9.382/2017, que dispõe sobre o exercício profissional e condições de trabalho do profissional tradutor, guia-intérprete e intérprete de Libras, que revogaria a Lei ํㅜ 12.319, de 1ํㅡㄹ de setembro de 2010 (BRASIL, 2010).

A medida propõe que,

Art. 5ำ A duração do trabalho dos profissionais de que trata essa Lei será de 6 (seis) horas diárias ou de 30 (trinta horas semanais). Parágrafo único. 0 trabalho de tradução e interpretação superior a uma hora de duração deverá ser realizado em regime de revezamento, com, no mínimo, 2 (dois) profissionais.

Enquanto a Lei no 12.319/10 normatiza a profissão de Tradutor e Intérprete da Língua Brasileira de Sinais, apresenta suas funções e a capacitação exigida para o exercício do cargo, o Projeto de Lei no 9382/2017 também regulamenta a profissão de guiaintérprete, bem como suas funções e capacitação necessária e propõe a duração de trabalho dos profissionais e o revezamento em casos de trabalho superior a uma hora. Como afirma Bueno (2013), as horas laborais e o revezamento têm grande influência na qualidade do trabalho e até mesmo na saúde dos intérpretes, uma vez que a função exige grande esforço físico e mental. Em um ambiente em que a presença desse profissional é imprescindível, é muito importante pensar nas condições de trabalho e na logística para que todos os alunos com surdocegueira disponham de acessibilidade.

Sobre a modulação de voz, ela é mencionada como prática pedagógica, pois é uma atitude importante quando se trata de alunos com resíduo auditivo e que tenham a fala ampliada como forma de recepção da informação. Ao atuar com esse público, o professor deve estar atento à altura da voz, à velocidade em que fala e até mesmo à sua diç̧ão (maneira de articular ou pronunciar palavras), uma vez que todos esses aspectos influenciam na qualidade em que a informação chega até o discente.

As instruções táteis foram destacadas no estudo, pois apesar de também serem comuns com as pessoas com deficiência visual, em certas circunstâncias, tornamse indispensáveis para os alunos com surdocegueira, principalmente quando são usuários de Libras e os professores não dominam a língua, e também nos casos em que o aluno 
não possui comunicação formal estabelecida (comunicação por sinais caseiros e expressões faciais e corporais). Estratégias como a do professor de Orientação e Mobilidade, que realiza o movimento junto com o aluno para que ele compreenda como deve executar a tarefa, vêm sendo realizadas há algum tempo no campo da surdocegueira. O professor e sociólogo Jan Van Dijk, em 1989, apresentou procedimentos que podem auxiliar no desenvolvimento de comunicação de crianças com surdocegueira congênita. Um deles é chamado de ressonância (BRASIL, 2006):

\begin{abstract}
A ressonância consiste no movimento corpo a corpo, sendo que a iniciativa do movimento parte da criança. O objetivo desta fase consiste no estabelecimento dos primeiros contatos com a criança e na introdução de modalidades de comunicação baseadas no movimento. Neste período, estabelece-se um vínculo corporal entre o adulto e a criança, a partir do qual o adulto passa a fazer parte do universo dela. A ação corporal permite estabelecer um diálogo por meio do movimento. (BRASIL, 2006, p. 18)
\end{abstract}

Por meio da ação corpo a corpo, o docente consegue comunicar qual é a tarefa e como ela deve ser executada pelo aluno. Apesar de ser uma prática criada para a comunicação de crianças, pode ser empregada com alunos de qualquer idade, variando a complexidade da informação. Logo, pode ser vista como uma modalidade comunicacional com base em movimento.

\title{
Capacitação Profissional
}

Os docentes de Cerâmica e Educação Física buscaram capacitação em curso de Língua Brasileira de Sinais a partir da dificuldade que encontraram para se comunicar com os alunos. O profissional de Braille já havia feito curso de Libras antes de ingressar na Instituição. Atualmente, os professores de Cerâmica e Braille têm o suporte do intérprete de Libras quando precisam comunicar informações mais complexas ou em atividades em que há mais de um aluno com a deficiência.

O Decreto no 5.626/05 (BRASIL, 2005) garante a inserção da Libras como disciplina curricular obrigatória em todos os cursos de licenciatura, nas diferentes áreas do conhecimento e de cursos de formação de professores e profissionais da educação para o exercício do magistério. No entanto, o pouco tempo destinado ao estudo da língua não garante que o professor tenha proficiência e aprenda o vocabulário específico de sua área de atuação. Lemos e Chaves (2012) realizaram uma investigação em seis instituições federais de Ensino Superior e constataram que a carga horária destinada à disciplina de Libras varia de 30 a 68 horas e não há enfoque no vocabulário específico dos cursos em 
que a disciplina foi incluída. Dessa maneira, a formação continuada na Língua Brasileira de Sinais foi a solução encontrada por alguns professores que atuam no Programa de Reabilitação para estabelecerem uma melhor comunicação com os discentes com surdocegueira. Mesmo nesses casos, a presença do intérprete continua sendo fundamental para comunicar informações mais complexas e auxiliar as aulas em que há a presença de mais de um aluno com surdocegueira.

Os professores de Cerâmica, Artes Visuais, Braille e Educação Física declararam ter participado de grupo de pesquisa específico sobre a surdocegueira ou que aborde a temática. Todos informaram que o conhecimento teórico sobre as características da deficiência foi importante para refletirem acerca das práticas específicas para esse público.

\title{
Material e Métodos
}

Foi considerada adaptação de método de ensino os casos dos professores de Braille e Artes Plásticas. O primeiro alterou a ordem em que geralmente ensinava os conteúdos para que o aluno entendesse com mais clareza os conceitos abordados em aula, e o segundo alterou as atividades de leitura e escrita do conteúdo, respeitando a estrutura da primeira língua do discente, a Libras, possibilitando melhor compreensão.

Quanto ao primeiro caso, durante a observação direta das aulas, notou-se que o professor de Artes utilizou materiais concretos, pediu que o aluno os reproduzisse em desenhos bidimensionais para posteriormente inserir os conceitos do campo da arte. Esse tipo de recurso é comum entre pessoas surdas usuárias da língua de sinais e deve ser incorporado nas aulas para favorecer a aprendizagem (LACERDA; SANTOS; CAETANO, 2011),

\begin{abstract}
Assim, um elemento imagético (uma maquete, um desenho, um mapa, um gráfico, uma fotografia, um vídeo, um pequeno trecho de filme) poderia ser um material útil à apresentação de um tema ou conteúdo pelos professores de ciências, física, química, biologia, história, geografia, matemática, inglês, entre outros. Um elemento visual que provocasse debate, que trouxesse a tona conceitos, opiniões e que pudesse ser aprofundado na direção dos objetivos pretendidos pelo professor. (LACERDA; SANTOS; CAETANO, 2011, p. 105)
\end{abstract}

O aluno em questão nasceu surdo, tem a Libras como primeira língua e começou a perder a visão na vida adulta. Após a diminuição da capacidade visual, o discente passou a receber as informações não apenas pela comunicação visual-espacial, uma característica das línguas gestuais, mas também pelo tato. Logo, sua experiência com a aquisição de conceitos não difere muito das experiências dos alunos surdos. 
Além disso, observa-se que o intérprete não está presente nas aulas como um simples tradutor de informações. A afirmação do docente demonstra que há uma relação colaborativa entre os profissionais. A sugestão do intérprete possibilitou que os conceitos fossem transmitidos de forma mais clara para 0 aluno com surdocegueira. Como afirma Kotaki e Lacerda,

Nesse sentido, o trabalho do professor em parceria com o intérprete educacional é relevante na qualidade de ensino à pessoa surda. Deve existir, entre eles, um planejamento comum todos os dias, discutir e compartilhar ideias, refletir sobre as aulas diárias, e ter oportunidade de sugerir adaptações e modificações para atender todas as necessidades daquele aluno, facilitando o trabalho de interpretação como também de acesso às informações e aprendizado do surdo. (KOTAKI; LACERDA, 2011, p. 135)

A adaptação necessária para o aluno com surdocegueira, respeitando a sua especificidade de comunicação, pode gerar melhor aproveitamento e assimilação de conceitos.

Quanto ao ensino do Sistema Braille, cabe recordar que no Brasil, ao se escrever com o código, utiliza-se a língua portuguesa com todas as suas características estruturais e se registra com a grafia do Sistema. No caso de uma pessoa surda, o português é sua segunda língua e a língua de sinais a primeira, de forma que o modo de ensino-aprendizagem do português será na modalidade escrita. Nessa perspectiva, "o ensino de uma segunda língua deixa de ser um processo de explicitação e domínio rígido de estruturas" (BRASIL, 2004). Assim, analisando-se a prática do docente, compreende-se a razão pela qual foi flexibilizado o ensino do Braille, uma vez que a primeira língua do aluno é a Libras.

Durante a observação direta das aulas, a pesquisadora perguntou ao professor como eram essas adaptações de acordo com a estrutura da língua de sinais. O docente afirmou que o aluno tem liberdade em escrever em Braille usando a estrutura da Libras em seus exercícios. O aluno geralmente omite algumas preposições e usa os verbos no infinitivo, quando em português seriam flexionados. Nas atividades redigidas pelo professor, as orações são escritas tanto com a estrutura da língua portuguesa, como semelhantes à Libras. Também há preferência na elaboração de orações mais curtas para facilitar a compreensão. Assim, o professor não deixa de mostrar como é a estrutura do português, como também não considera incorreta a estrutura da Libras. O foco do ensino está em redigir e compreender as informações em Braille. 
Cabe informar que durante o levantamento bibliográfico foram encontradas três pesquisas que abordam a questão da leitura e da escrita de pessoas com surdocegueira. Entretanto, nenhuma delas aborda o método utilizado pelo docente em questão (COSTA; CADER-NASCIMENTO, 2005; AGOSTINI; COSTA, 2006; CADER-NASCIMENTO; FAULSTICH, 2016). Dessa forma, pode-se dizer que o professor de Braille criou um método de ensino do Sistema para pessoas com surdocegueira usuárias de Libras.

Os profissionais de Braille e Artes Plásticas mencionaram o emprego de materiais concretos em suas aulas para facilitar a assimilação do conteúdo. Pode-se considerar que "A progressão do sistema de comunicação geralmente parte do concreto para o abstrato" (BRASIL, 2006, p. 33), sendo assim, a utilização de materiais concretos possibilita uma melhor comunicação, o que é de suma importância na aprendizagem de questões mais complexas e abstratas. Tanto para alunos com deficiência visual quanto com surdocegueira,

[...] a utilização de materiais concretos se torna imprescindível, haja vista que tem no concreto, no palpável, seu ponto de apoio para as abstrações. Ele tem no tato seu sentido mais precioso, pois é através da exploração tátil que lhe chega a maior parte das informações. É através dela que ele tem a possibilidade de discernir objetos e formar idéias. (FERRONATO, 2002, p. 41)

Um aspecto observado nas entrevistas é que os professores de Artes (Visuais e de Cerâmica), apesar de ministrarem a mesma disciplina, têm opiniões diversas em relação aos materiais didáticos específicos para alunos com surdocegueira. Enquanto o profissional de Cerâmica afirma que existe a necessidade de pensar em adaptações de materiais para esse público, o profissional de Artes Visuais assegura que são usados os mesmos materiais para todos os alunos. Possivelmente, o fato de trabalharem conteúdos distintos influencie na relevância de serem criados materiais específicos para educandos com surdocegueira.

Com relação às aulas individuais, os professores de O.M. e Braille afirmaram fazer uso dessa prática. Ela é comum em alguns tipos de atendimentos do Programa de Reabilitação, em que o conteúdo deve ser flexibilizado de acordo com a necessidade (atividades desenvolvidas no cotidiano do aluno e graus de perdas sensoriais distintos) e interesses de cada educando.

A aula individualizada é prevista na Lei Brasileira de Inclusão. Cabe ao poder público assegurar, criar, desenvolver, implementar, incentivar, acompanhar e avaliar: 
Art. 27. V - adoção de medidas individualizadas e coletivas em ambientes que maximizem o desenvolvimento acadêmico e social dos estudantes com deficiência, favorecendo o acesso, a permanência, a participação e a aprendizagem em instituições de ensino; (BRASIL, 2015)

Os docentes de Cerâmica e Artes Visuais descreveram a necessidade de realizar atividades individuais para atender a especificidade dos discentes. O profissional de Educação Física teve alunos com surdocegueira inclusos e também ministrou aulas individuais, uma vez que um dos alunos não gostava de contato físico e apresentava outros comprometimentos além da surdocegueira.

Quanto ao trabalho colaborativo, considerando o conceito de Libâneo (1994) de que os métodos de ensino são as ações do professor visando à organização das atividades de ensino para atingir objetivos em relação a um conteúdo específico, o item foi inserido nessa categoria por ser compreendido como uma ação docente conjunta, objetivando melhor atendimento dos alunos, de acordo com suas especificidades, a fim de atingir os objetivos traçados.

O profissional de Cerâmica considerou importante a presença de um professor do PAAS nas aulas. Essa articulação entre os pares possibilita que o professor do Programa observe diretamente o desenvolvimento do aluno, dê sugestões para melhor atender às especificidades e colha informações que possam ser pertinentes para o atendimento individualizado, sendo uma troca proveitosa para ambos e para a evolução do aluno. Para Loiola,

[...] o trabalho colaborativo entre docentes constitui-se em excelente espaço de aprendizagem, permitindo a identificação de suas forças, fraquezas, dúvidas e necessidades de reconstrução, a socialização de conhecimentos, a formação de identidade grupal e a transformação de suas práticas pedagógicas. (LOIOLA, 2005, p. 220).

Em suma, para Cambruzzi e Costa (2016), os serviços educacionais destinados às pessoas com surdocegueira ainda estão distantes de promover a inclusão com qualidade, entretanto, nesse estudo, vê-se que algumas ações já vêm sendo realizadas para que os alunos com surdocegueira possam participar ativamente das atividades oferecidas pela Instituição.

A surdocegueira ainda é uma modalidade relativamente nova na Educação Especial, bem como a compreensão das necessidades educacionais e sociais desses indivíduos (LEME, 2015). Logo, muito ainda deve ser feito para que esse público tenha igualdade de condições. Medidas como a formação continuada e a presença de mais profissionais 
capacitados, principalmente guias-intérpretes, são indispensáveis para que se dê seguimento ao processo de inclusão. Como afirma Reyes (2004), a comunicação é a chave para a inserção social e também educacional da pessoa com surdocegueira, portanto, tudo que está relacionado a essa questão requer maior atenção e interesse.

\section{Conclusão}

A presente pesquisa relatou e analisou as práticas pedagógicas utilizadas pelos professores no processo de reabilitação de alunos com surdocegueira do Instituto Benjamin Constant. Os resultados obtidos demonstram que a comunicação é a maior dificuldade encontrada no processo ensino-aprendizagem dos discentes com surdocegueira. O principal entrave encontra-se na comunicação de alunos que são usuários da Língua Brasileira de Sinais e que, com isso, a presença do tradutor e intérprete de Libras é fundamental para auxiliar na comunicação entre professor e aluno, bem como a capacitação do próprio docente na língua de sinais. As ações mais significativas relatadas nas entrevistas foram a adaptação de material didático pedagógico, a adaptação de método de ensino, o auxílio de tradutor e intérprete de Libras, o trabalho colaborativo, a modulação de voz para o aluno com baixa audição, as instruções táteis, os materiais concretos, a capacitação em curso de Libras, a participação em grupo de estudos e as necessidades da realização de atividades individualizadas com os alunos.

Outro aspecto observado durante a análise das práticas pedagógicas é que, apesar de ser uma deficiência única e não o somatório da deficiência visual com a auditiva, muitas das ações realizadas no atendimento ao público com surdocegueira são com base nas práticas pedagógicas empregadas na educação de pessoas com deficiência visual e deficiência auditiva. Geralmente, o que define essa relação são o grau de perda do aluno e a língua que ele faz uso, como, por exemplo, o caso dos alunos com surdocegueira usuários da Língua Brasileira de Sinais.

As práticas pedagógicas vêm possibilitando a participação dos alunos nas aulas mencionadas e comprovam que é possível a inclusão das pessoas com surdocegueira em um ambiente de alunos com deficiência visual. Apesar de não ser uma prática fácil, ainda é considerada viável, que demanda diálogo entre os profissionais que atuam com esses estudantes, aulas e momentos individualizados, estudos sobre a deficiência e a especificidade de cada aluno. 
Acredita-se que muitos passos devam ser dados para que novas práticas pedagógicas surjam e atendam aos alunos com surdocegueira, principalmente àqueles com perda total da visão e da audição. Novas investigações devem ser elaboradas para se buscar compreender como são as práticas pedagógicas em outros ambientes e níveis educacionais. $O$ intuito da pesquisa foi relatar as práticas pedagógicas específicas que vêm sendo utilizadas no processo de reabilitação de alunos com surdocegueira e que cada um deles deve ser respeitado dentro de suas características específicas, principalmente no que se refere à sua forma de comunicação e de percepção do mundo.

\section{Referências}

AGOSTINI, Elaine Aparecida Macahdo de; COSTA, Maria da Piedade Resende da. Aplicação de um programa para o ensino da leitura e escrita de palavras para o aluno com surdocegueira. Série-Estudos - Periódico do Programa de Pós-Graduação em Educação da UCDB, n. 22, jul./dez. 2006.

BARDIN, L. Análise de Conteúdo. Lisboa: Edições 70, 1973.

BRASIL. Surdocegueira e Deficiência Múltipla. Coleção A Educação Especial na Perspectiva da Inclusão Escolar. Brasília: Ministério da Educação, 2010.

BRASIL. Ministério da Educação. Programa de Capacitação de Recursos Humanos do Ensino Fundamental: deficiência visual. Brasília: Ministério da Educação, Secretaria de Educação Especial, 2001.

BRASIL. Decreto N ำ 5.296, de 2 de dezembro de 2004.

BRASIL. Decreto ํㅜ 5.626, de 22 de dezembro de 2005.

BRASIL. Ministério da Educação. Secretaria de Educação Especial. Declaração dos Direitos das pessoas deficientes. Lei № 13.146, de 6 de julho de 2015.

BUENO, Carolina da Silva. A necessidade de revezamento do interprete educacional; 2013; Orientação de outra natureza; (Técnico em Tradução e Interpretação de LIBRAS) Escola São Jorge - CAT. Disponível em: http://www.ambitojuridico.com.br/site/index.php?n_link=revista_artigos_leitura\&artigo_id=1 7343\&revista_cader

CADER-NASCIMENTO, Fatima Ali Abdalah Abdel; FAULSTICH, Enilde. Expressão linguística e a produção escrita de surdocegos. Revista Moara - Edição 45 - jan/jun. 2016.

CAMBRUZZI, Rita C. S.; COSTA, Maria P. R.. Surdocegueira por Síndrome de Usher: recursos pedagógicos. São Paulo: EdUSCar, 2016. 
COMISSÃO DE DEFESA DOS DIREITOS DAS PESSOAS COM DEFICIÊNCIA. Projeto de Lei ํo 9382/2017. Brasília, 2017. Disponível em: http://www.camara.gov.br/proposicoesWeb/prop_mostrarintegra;jsessionid=BAD17065A4 8120BAC1DE424EA9849439. proposicoesWebExterno2? codteor $=1634551 \&$ filename $=\mathrm{PL}+$ 9382/2017

COSTA, Maria da Piedade Resende da; CADER-NASCIMENTO, Fatima Ali Abdalah Abdel. O ensino da leitura e escrita para estudantes surdocegas. Educação Especial n. 15. 2005.

FERRONATO, Rubens. A construção de instrumento de inclusão no ensino de matemática. 2002. 126 f. Dissertação (Mestrado em Engenharia de Produção) Universidade Federal de Santa Catarina, Florianópolis, 2002.

GATTI, B. A. Análise das políticas públicas para formação continuada no Brasil, na última década. Revista Brasileira de Educação. Rio de Janeiro: ANPEd, v. 13 n. 37 jan/abr. 2008.

GIL, Antonio Carlos. Como elaborar projetos de pesquisa. 4 ed. São Paulo: Atlas, 2002.

KOTAKI, Cristiane Satiko; LACERDA, Cristina Broglia Feitosa de. 0 intérprete de língua brasileira de sinais no contexto da escola inclusiva: focalizando sua atuação na segunda etapa do ensino fundamental. In: Coleção UAB-UFSCar - Língua brasileira de sinais - Libras. São Carlos: [S.n.], 2011.

LACERDA, Cristina Broglia Feitosa de; SANTOS, Lara Ferreira dos; CAETANO, Juliana Fonseca. Estratégias metodológicas para o ensino de alunos surdos. In: Coleção UAB-UFSCar - Língua brasileira de sinais - Libras. São Carlos: [S.n.], 2011.

LEME, Carolina G. O papel do instrutor mediador e o impacto da tecnologia assistiva frente à inclusão de alunos com surdocegueira. Dissertação, UNOPAR, Londrina, 2015.

LEMOS, Andréa Michiles; CHAVES, Ernando Pinheiro. A disciplina de Libras no ensino superior: da proposição à prática de ensino como segunda língua. Anais do XVI ENDIPE Encontro Nacional de Didática e Práticas de Ensino - UNICAMP - Campinas - 2012. Disponível em: http://www.infoteca.inf.br/endipe/smarty/emplates/arquivos template/upload_arquivos/acervo/docs/2190c.pdf

LIBÂNEO, José Carlos. Didática. São Paulo : Cortez, 1994.

LOIOLA, L. J. S L. Contribuições da pesquisa colaborativa e do saber prático contextualizado para uma proposta de formação continuada de professores de educação infantil. In: 28a․ REUNIÃO ANUAL DA ANPED, 14-18 out, 2005.

MAIA, Shirley R. Descobrindo crianças com surdocegueira e deficiência múltipla sensorial, no brincar. 2011. 240f. Tese (Doutorado) - Universidade resbiteriana Mackenzie. São Paulo, 2011.

NASCIMENTO, F. A. A. A. C. Saberes e práticas da inclusão: dificuldades de comunicação e sinalização: surdocegueira/múltipla deficiência sensorial. [4. ed.] / 
elaboração prof ${ }^{\mathrm{a}}$ ms. Fátima Ali Abdalah Abdel Cader Nascimento - Universidade Federal de São Carlos - UFSC/SP, prof. Shirley Rodrigues Maia - Associação Educacional para a Múltipla Deficiência - AHIMSA. - Brasília: MEC, Secretaria de Educação Especial, 2006.

NICOLAIEWSKY, C. A.; CORREA, J. Escrita ortográfica e revisão de texto em Braille: Uma história de reconstrução de paradigmas sobre o aprender. Cad. Cedes, Campinas, v. 28 , n. 75 , p. 229-244, maio/ago. 2008.

PLETSCH, M. D.; SOUZA, F. F.; ORLEANS, L. F..A diferenciação curricular e o desenho universal na aprendizagem como princípios para a inclusão escolar. Revista Educação e Cultura Contemporânea, São Paulo, v. 14, n 35, 2017.

REYES D. A. La sordoceguera: un análisis multidisciplinar. Madrid: ONCE, 2004.

WATANABE, Dalva Rosa. 0 estado da arte da produção científica na área da surdocegueira no Brasil de 1999 a 2015. São Paulo, 2017. 262 p. Dissertação (Mestrado - Programa de Pós-Graduação em Educação. Área de Concentração: Educação Especial), Faculdade de Educação da Universidade de São Paulo, São Paulo, 2017.

VEIGA, IIma Passos Alencastro. A prática pedagógica do professor de didática. Campinas, SP: Papirus, 1989.

VYGOTSKY. L. S. Obras completas. Tomo cinco: Fundamentos de Defectologia. Havana: Editorial Pueblo Y Educación, 1989.

YIN, Robert K. Estudo de Caso: planejamento e métodos. 3 ed. Porto Alegre: Bookman, 2005.

\section{Correspondência}

Thaís Ferreira Bigate - Instituto Benjamin Constant. Av. Pasteur, 350 / 368 - Urca, Rio de Janeiro.CEP: 22290-240. Rio de Janeiro, Rio de Janeiro Brasil.

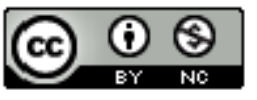

This work is licensed under a Creative Commons Attribution-NonCommercial 4.0 International (CC BY-NC 4.0) 